\title{
Lateral Force during Curve Negotiation of Forced Steering Bogies
}

\author{
Eisaku SATO, Dr.Eng. \\ Senior Researcher, Laboratory Head, \\ Vehicle Dynamics
}

\author{
Hideyuki KOBAYASHI \\ Senior Researcher, Running Gear \\ Vehicle Structure Technology Div. \\ Isao OKAMOTO \\ Director
}

\author{
Kazuhiko TEZUKA \\ General Manager
}

\author{
Hirohiko KAKINUMA \\ Executive Director \& General Manager of Railway Operations Headquarters \\ Hokkaido Railway Company
}

\section{Toshiharu TAMAOKI}

General Manager Transport Department Hokkaido Railway Company

\begin{abstract}
In order to shorten the travel time of limited express trains operated between Sapporo and Kusiro in Japan, a tilting diesel car called series DC283 (passenger car for a limited express train) with forced steering bogies (DC283 forced steering bogies) has been developed by JR Hokkaido and RTRI. This paper describes the lateral force between wheel and rail observed with this test car on curve and that obtained from coresponding computer simulations. The results of simulations and field tests are as follows. (1) DC283 forced steering bogie can reduce the lateral force between wheel and rail. (2) The decrease of the lateral force due to the forced steering bogie should be verified not only on circular curves but also on transition curves. (3) The lateral force of the first wheelset is the largest. (4) To decrease the lateral force more effectively, the steering ratio is set 35 percent $(L v=1.35)$ higher than the value that makes the radial position. (5) The running stability at the maximum speed of $140 \mathrm{~km} / \mathrm{h}$ is satisfactory in field tests.
\end{abstract}

Keywords : forced steering bogie, lateral force, curve negotiation, vehicle dynamics, simulation, field test, wheel/rail

\section{Introduction}

The narrow gauge railway lines in Japan have many small-radius curves. Therefore, various forced steering bogies have been developed to reduce the lateral force of wheel and increase the curve negotiating speed of trains. One is a bogie of longitudinally asymmetric structure ${ }^{1)}$ that has commercially been used since 1996. Another is the DC283 forced steering bogie ${ }^{2)}$ used for type 283 tilting diesel cars that has been used for limited express trains between Sapporo and Kushiro since 1997. On curves, the DC283 forcedly steers the wheelset with links according to the relative yawing angle between car body and bogie which is called "a bogie angle." This type of forced steering bogie has been studied and developed around the world ${ }^{3), 4), 5)}$. This paper compares the DC283 forced steering with a conventional bogie, and describes the influence of steering quantity on the lateral force of the forced steering bogie in curve negotiation based on the results of computer simulation and field test data.

\section{Outline of bogie and steering mechanism}

Figure 2, 3 and 4 show a DC283 (Fig. 1) bogie, the steering mechanism and a vehicle model, respectively.

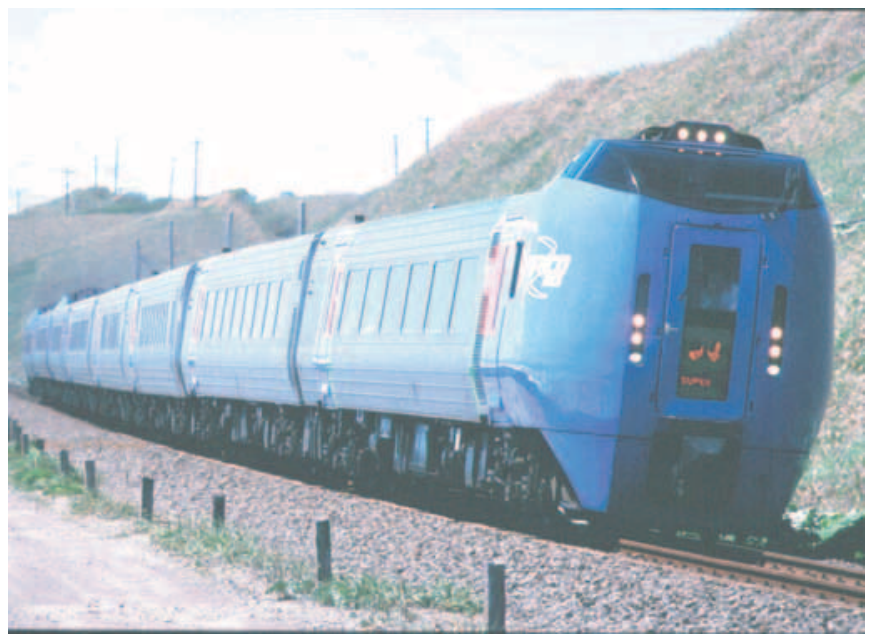

Fig. 1 DC283: Limited express tilting diesel car with forced steering bogies

The mechanism of the steering system is as follows.

(1) When the car comes onto a curve, the angle between bogie and body generates an angle between the steering beam and bogie frame. The angle is called "a bogie angle."

(2) When a bogie angle is generated on curve, the steer- 


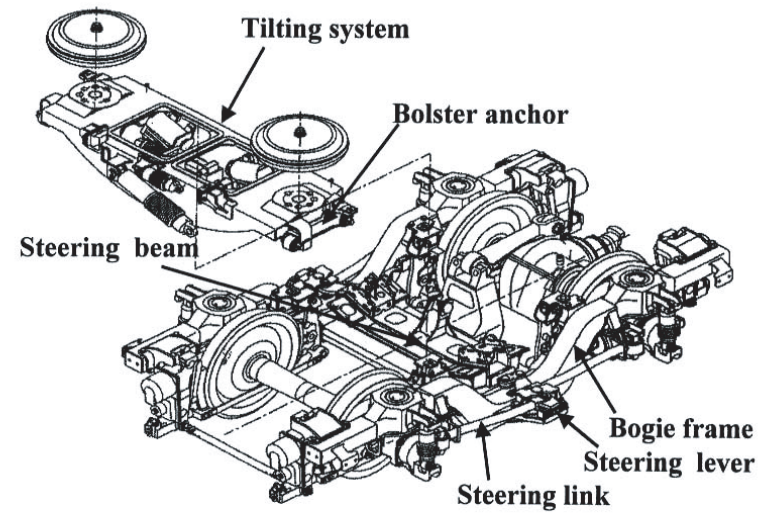

Fig. 2 DC283 forced steering bogie

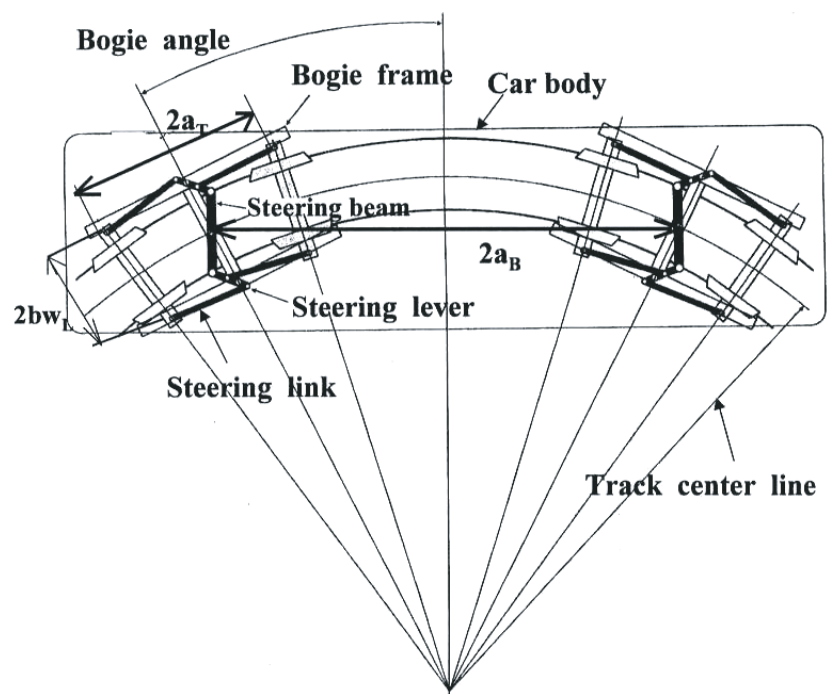

Fig. 3 Steering mechanism for DC283 forced steering bogie

ing lever turns and the steering link moves the left and right axle boxes into the longitudinal direction.

The quantity of steering $\Delta X$ is the longitudinal displacement of steering link expressed by the following equation.

$$
\begin{aligned}
& \Delta X=\left(L_{B} / L_{A}\right) b_{t}\left(\psi_{B}-\psi_{T}\right) \\
& =L_{v}\left(a_{T} / a_{B}\right) b_{W L}\left(\psi_{B}-\psi_{T}\right)
\end{aligned}
$$

$L_{B} / L_{A}$ : lever ratio (see Fig. 3 and Fig. 4 )

$L v$ : Steering ratio

$a_{T}, a_{B}, b_{W L}, b_{t}$ (see Fig. 3 and Fig. 4 )

$\psi_{B}, \psi_{T}$ : Yaw angle of car body and bogie frame

$L v$ means a surcharge of quantity of steering that is called the steering ratio. For example, $L v=1.0$ is the steering quantity for a radial position. $L v=1.35$ is the steering quantity of $35 \%$ surcharge for the radial position. $L v=0.0$ is the steering ratio of the conventional bogie without a steering system. The effect to reduce the lateral force changes depending on the steering ratio $L v$. This effect is estimated by computer simulation.

\section{Computer simulation}

\subsection{Vehicle model}

Figure 4 shows a vehicle model. There are side bearers on the bogie cross beam, and the steering beam turns in the yaw direction around the center pin, to slide the top of side bearers. The steering beam is connected with a tilting beam. The tilting beam is connected with the car body by bolster anchors. Therefore, the steering beam, tilting beam and car body are fixed in the yaw direction. By the longitudinal stiffness of bolster anchor and resistance of side bearer frictional force, a resisting moment acts between car body and bogie. Because the influence of tilting movement on the wheel load and lateral force is small, the tilting movement is ignored. A nonlinear model is used in curving simulation. The factors considered as directions of motion are the yawing displacement, rolling displacement and lateral displacement for the vehicle, and lateral displacement for the rail. For the creep force, the saturation characteristics are considered according to the equation of Levi-Charte. As the information on the contact between wheel and rail, two-dimensional contact informations in the case of the yawing angle 0 are used. For hunting motion analysis, an eigenvalue analysis is used as a calculation model. Accordingly, the saturation characteristics of the creep force and nonlinearity of side bearer frictional force are ignored. The wheel of DC283 forced steering bogie use a conic profile tread.

\section{Notation and numerical value}

$m_{W}:$ Mass of wheelset $(1,180 \mathrm{~kg})$

$m_{T}$ : Mass of bogie frame $(3,870 \mathrm{~kg})$

$m_{B}$ : Mass of car body $(3,200 \mathrm{~kg})$

$m_{r}:$ Equivalent mass of rail $(1,380 \mathrm{~kg})$

$i_{B X}$ : Moment of inertia of body in roll $(1.04 \mathrm{~m})$

$i_{B Z}:$ Moment of inertia of body in yaw $(6.06 \mathrm{~m})$

$i_{T X}$ : Moment of inertia of bogie frame in roll $(0.56 \mathrm{~m})$

$i_{T Z}$ : Moment of inertia of bogie frame in yaw $(1.25 \mathrm{~m})$

$i_{W Z}$ : Moment of inertia of whelset in yaw $(0.61 \mathrm{~m})$

$k_{W X}$ : Suspension stiffness of journal box in $x$ direction $\left(2.75 \times 10^{6} \mathrm{~N} / \mathrm{m}\right)$

$k_{W y}$ : Suspension stiffness of journal box in $y$ direction (6.44 $\times 10^{6} \mathrm{~N} / \mathrm{m}$ )

$k_{W Z}$ : Suspension stiffness of journal box in $z$ direction $(9.0$ $\times 10^{5} \mathrm{~N} / \mathrm{m}$ )

$c_{W Z}$ : Damping coefficient of journal box in $z$ direction $(2.0$ $\left.\times 10^{4} \mathrm{Ns} / \mathrm{m}\right)$

$c_{W X}, c_{W y}$ : Damping coefficients of journal box in $x$ and $\mathrm{y}$ directions $(0 \mathrm{Ns} / \mathrm{m})$

$k_{T Z}$ : Siffness between body and tilting beam in $z$ direction $\left(3.0 \times 10^{5} \mathrm{~N} / \mathrm{m}\right)$

$k_{B}$ : Bolster anchor stiffness in $x$ direction $\left(7.5 \times 10^{5} \mathrm{~N} /\right.$ $\mathrm{m})$

$k_{T X}, k_{T y}$ : Stiffness between body and tilting beam in $x$ and $y$ directions

$c_{T y}$ : Damping coefficient between body and tilting beam in $y$ direction

$c_{T Z}$ : Damping coefficient between body and tilting beam in $z$ direction

$k_{T X},=k_{T y}=1.5 \times 10^{5} \mathrm{~N} / \mathrm{m} \quad c_{T y}=8.0 \times 10^{4} \mathrm{Ns} / \mathrm{m}$

$c_{T Z}=1.5 \times 10^{4} \mathrm{Ns} / \mathrm{m}$ 
DOF

Carbody +2 bogie frames

$$
(3 \times 3=9)
$$

Lateral

Yaw

Roll

4 wheelsets

$$
(2 \times 4=8)
$$

Lateral

Yaw

8 Rails (equivalent masses)

$$
(8 \times 1=8)
$$

Lateral

Total DOF :

(In the case of eigenvalue analysis,

DOF of rail is ignored. )
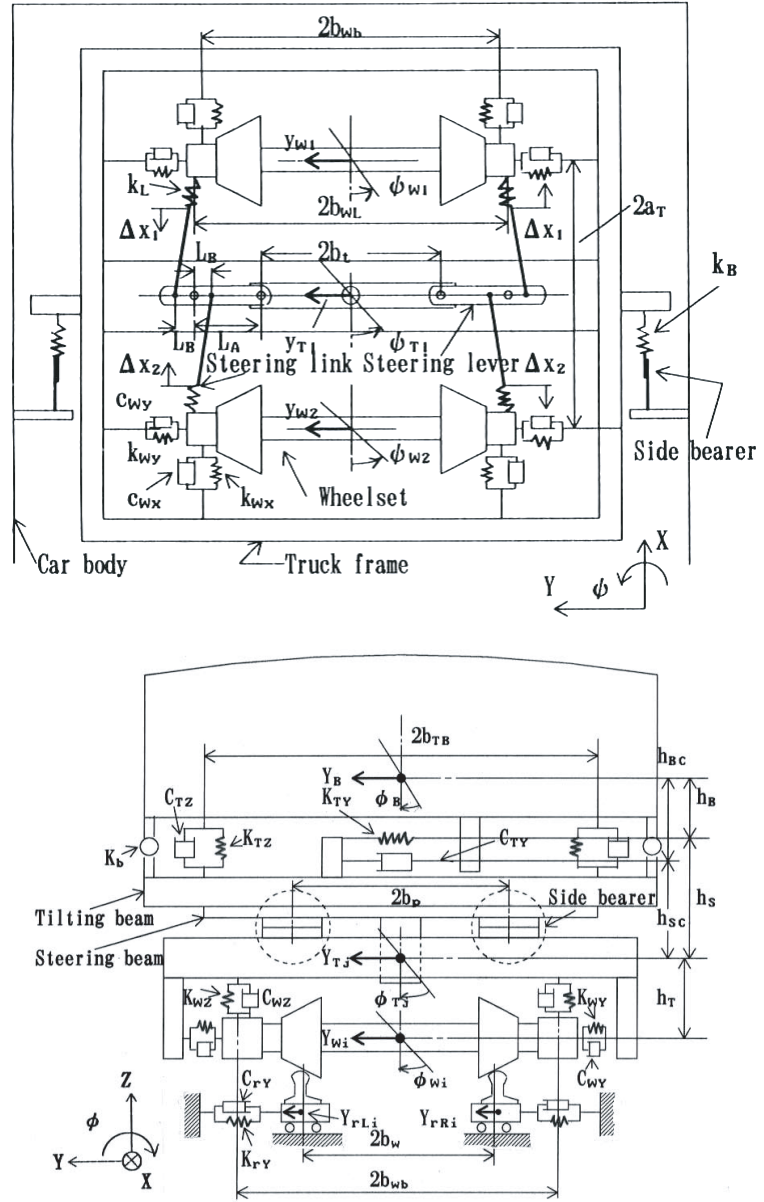

Fig. 4 Vehicle model

$k_{r y}$ : Suspension stiffness of track in $y$ direction $\left(1.5 \times 10^{7}\right.$ $\mathrm{N} / \mathrm{m})$

$c_{r y}$ : Damping coefficient of track in $y$ direction $\left(4.0 \times 10^{4}\right.$ $\mathrm{Ns} / \mathrm{m}$ )

$k_{L}$ : Suspension stiffness of steering link in $x$ direction $\left(3.9 \times 10^{7} \mathrm{~N} / \mathrm{m}\right)$

$L_{A}$ : Distance between center of steering lever and steering beam

$L_{B}$ : Distance between center of steering lever and steering link

$L_{V}$ : Steering ratio

$\Delta x_{i}$ : Longitudinal displacement of steering link

$2 b_{t}$ : Lateral distance between steering link and steering beam

$2 b_{\mathrm{WL}}$ : Lateral distance between steering links $(2.0 \mathrm{~m})$

$R$ : Radius of curve

$2 b_{W}=1.12 \mathrm{~m} \quad 2 b_{W b}=1.64 \mathrm{~m} \quad 2 b_{T b}=1.85 \mathrm{~m} \quad 2 a_{B}=14.4 \mathrm{~m}$ $2 a_{T}=2.15 \mathrm{~m}$

$2 b_{P}=1.0 \mathrm{~m} \quad \mathrm{~h}_{\mathrm{T}}=0.2 \mathrm{~m} \quad \mathrm{hs}=0.43 \mathrm{~m}$

$h_{s c}=0.35 \mathrm{~m} \quad h_{b}=0.41 \mathrm{~m} \quad h_{b c}=0.49 \mathrm{~m}$

Suffix $j: 1$ for front bogie frame and 2 for rear bogie frame Suffix $i: 1,2,3,4$ for wheelset No.1-No.4

\subsection{Prediction of steering efect}

3.2.1 Relation between lateral force and steering ratio
$Q_{1 L}:$ Inner lateral force

BTC : Beginning of transition curve

ETC : End of transition curve

BCC : Beginning of circular curve

ECC : End of circular curve

$Q_{1 R}$ : Outer lateral force
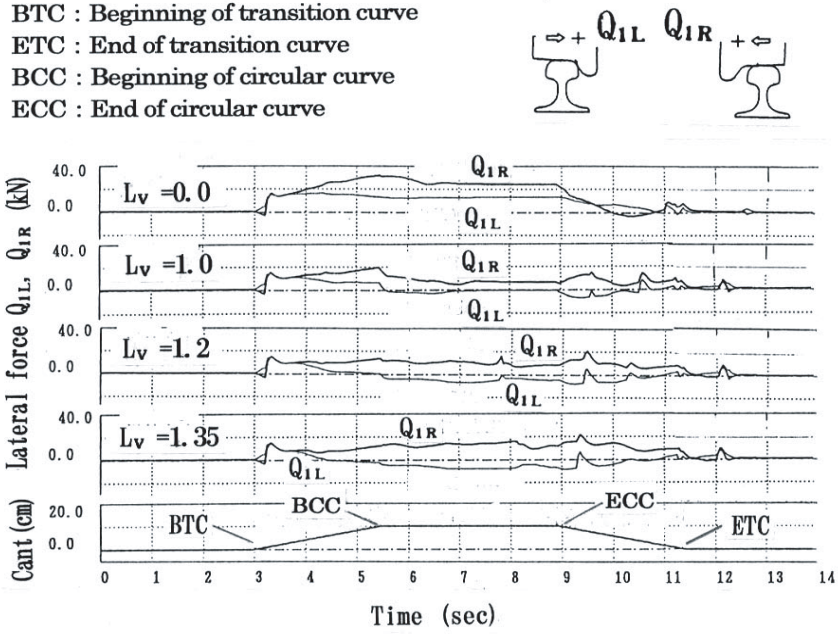

Fig. 5 Waveforms of lateral force : simulation $(R=302 \mathrm{~m}$, $V=88 \mathrm{~km} / \mathrm{h}$ )

Figure 5 shows the simulation waveforms of a conventional bogie $(L v=0)$ and forced steering bogie $(L v=1.0$, $L v=1.2, L v=1.35)$. The lateral force of the forced steering bogie is smaller than that of the conventional bogie. 


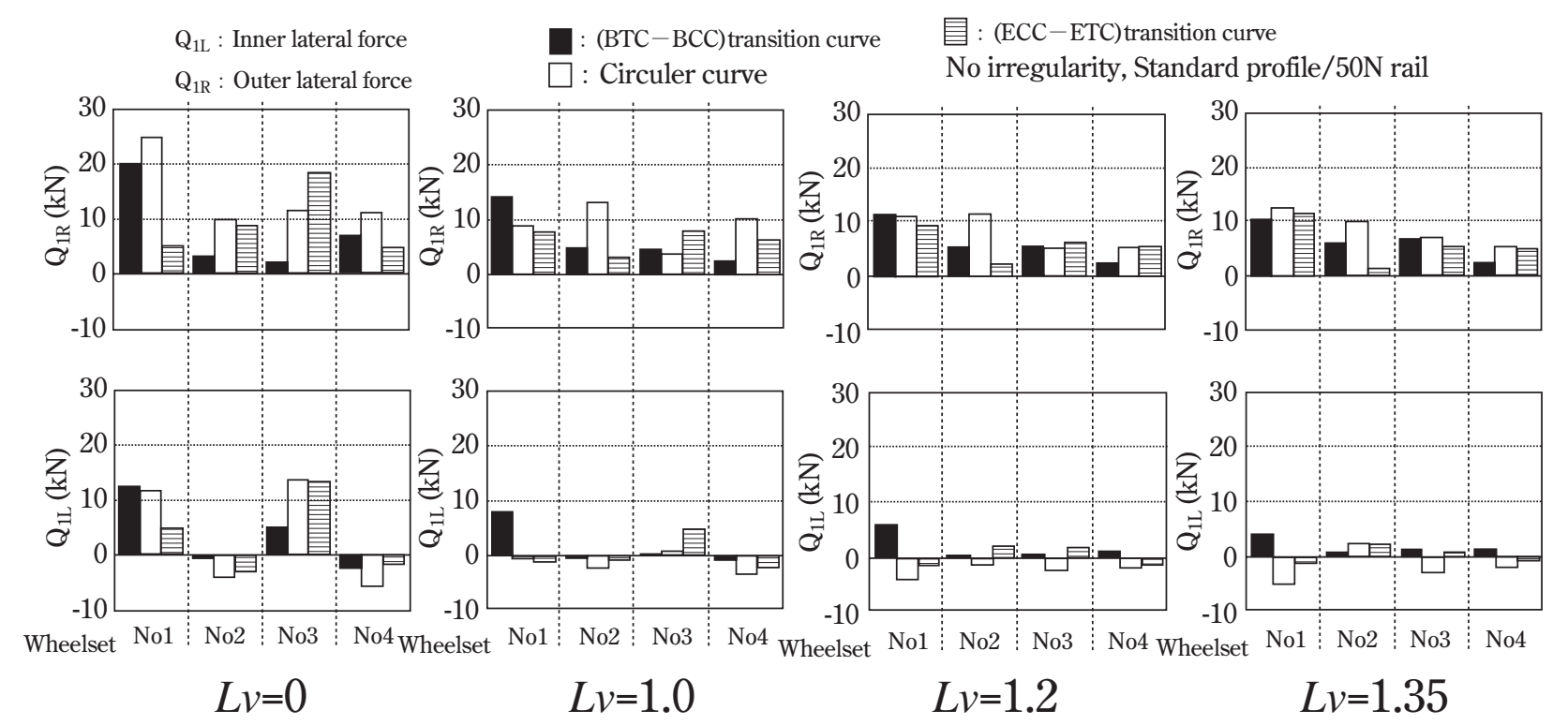

Fig. 6 Mean lateral force on curve : simulation $(R=302 \mathrm{~m}, V=88 \mathrm{~km} / \mathrm{h})$

In the case of $L v=1.0$, reduction of lateral force on the transition curve is smaller than that on a circular curve. The lateral force on the transition curve becomes smaller at $L v=1.2$ and $L v=1.35$ added with a surcharge of the quantity of steering. Accordingly, the effectiveness of the steering of forced steering bogie must be considered for both transition curves and the circular curves.

\subsubsection{Relation between lateral force and wheelset posi- tion}

Figure 6 shows the mean values of lateral force on each wheelset on transition and circular curves. In the case of conventional bogie, the difference of lateral force of wheelset No. 1 and No. 3 is larger than wheelset No. 2 and No. 4. However, in the case of forced steering bogie, the difference is smaller than that of the conventional bogie. In the case of $L v=1.0$, the lateral force of wheelset No.1 is larger than that of other wheelsets at the transition curve. As for $L v=1.2$ and $L v=1.35$, the lateral forces are smaller than those at $L v=1.0$. And the lateral force of the inner wheel of wheelset No. 1 has a negative value on a circular curve. The direction of the angle of attack varies from outer side to inner side of track when the quantity of steering is too large, and the lateral force becomes negative. As well as the conventional bogie, the lateral force of the forced steering bogie is the largest in wheelset No.1. Therefore, we concentrate on the lateral force of wheelset No. 1 and evaluate it. Then, we consider the time lag of steering on transition curves, the sliding resistance of the side bearers and select $L v=1.2$ $L v=1.35$ as the steering ratio of DC283 forced steering bogie.

\section{Results of hunting motion analysis}

\subsection{Eigenvalue analysis}

We evaluate the running stability by the damping ra- tio $\zeta$.

$$
\zeta=-\alpha / \sqrt{\alpha^{2}+\beta^{2}}
$$

$\zeta$ : Damping ratio

$\alpha$ : Real number

$\beta$ : Imaginary number

Figure 7-11 show the influence of each elements on the running stability at the speed of $200 \mathrm{~km} / \mathrm{h}$.

(1) Influence of bolster anchor stiffness

Figure 7 shows the influence of bolster anchor stiffness on the running stability. The figure shows that the running stability decreases when the bolster anchor stiffness is less than $200 \times 10^{4} \mathrm{~N} / \mathrm{m}$. Consequently, the bolster anchor stiffness is decided as $750 \times 10^{4} \mathrm{~N} / \mathrm{m}$.

(2) Influence of steering ratio

Figure 8 shows the influence of the steering ratio on the running stability. The running stability decreases as the steering ratio becomes larger. However, even if $L v$ equals 1.35 , the damping ratio is larger than 0.1 , and there are no problems.

(3) Influence of steering link stiffness

Figure 9 shows the influence of steering link stiffness on the running stability. The damping ratio does not decrease although the steering link stiffness becomes larger. We adopt $3,900 \times 10^{4} \mathrm{~N} / \mathrm{m}$ as the value of steering link stiffness to ensure the performance of steering.

(4) Influence of longitudinal journal box suspension stiffness

Figure 10 shows the influence of longitudinal journal box suspension stiffness on the running stability. The damping ratio does not decrease although the longitudinal stiffness of journal box suspension becomes smaller. Lower values of longitudinal stiffness of journal suspension are desirable for a forced steering bogie. We adopt the longitudinal journal box suspension of $275 \times 10^{4} \mathrm{~N} / \mathrm{m}$.

(5) Influence of speed

Figure 11 shows the influence of speed on the running stability. The damping ratio decreases, as the speed becomes higher. However, a damping ratio of about 0.3 is 


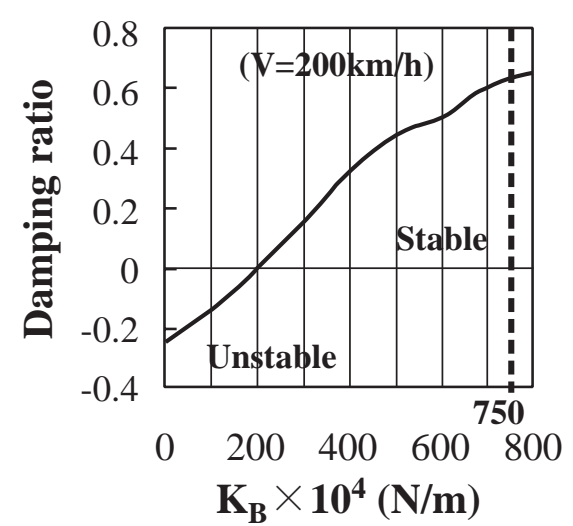

Fig. 7 Influence of bolster anchor stiffness

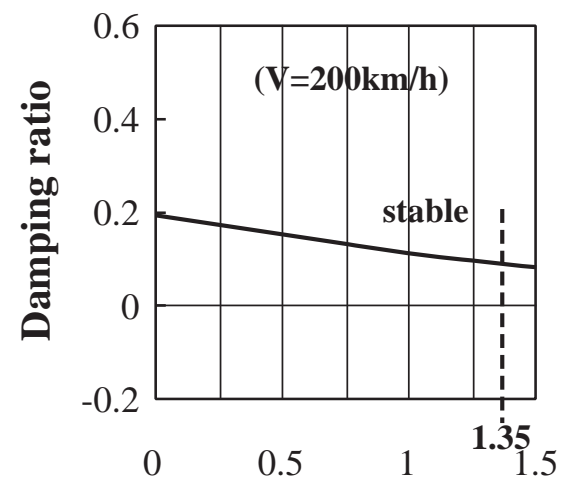

Lv : Steering ratio

Fig. 8 Influence of steering ratio

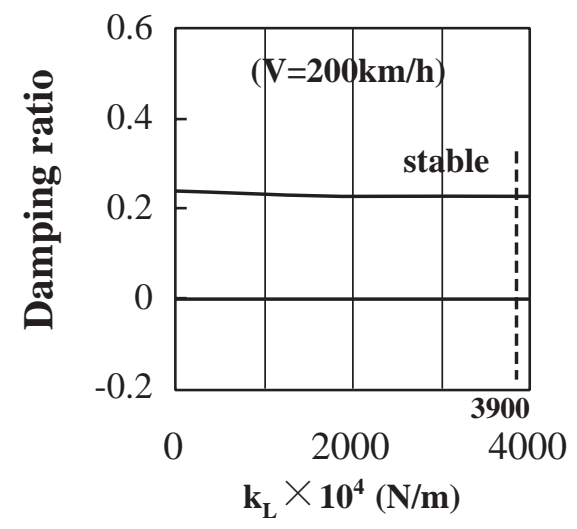

Fig. 9 Influence of steering link stiffness

satisfactory to ensure the running stability at the speed of $145 \mathrm{~km} / \mathrm{h}$

\subsection{Nonlinear simulation}

As a result of nonlinear simulation of running on a straight line, the critical speed of hunting of DC283 forced steering bogie is $280 \mathrm{~km} / \mathrm{h}$. Figure 12 shows an example waveform of simulation. The track irregularity is a lateral distortion of sinusoidal wave (wave length: $20 \mathrm{~m}$, amplitude 0-p: $7 \mathrm{~mm}$ ). From these results, DC283 forced steering bogie can ensure sufficient running stability at the maximum speed $(145 \mathrm{~km} / \mathrm{h})$.

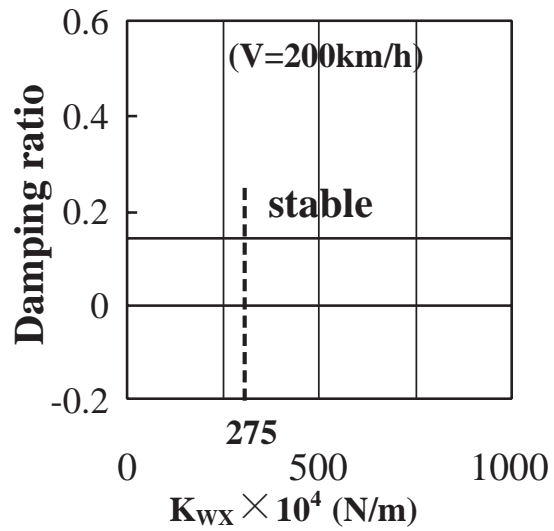

Fig. 10 Influence of longitudinal journal box stiffness

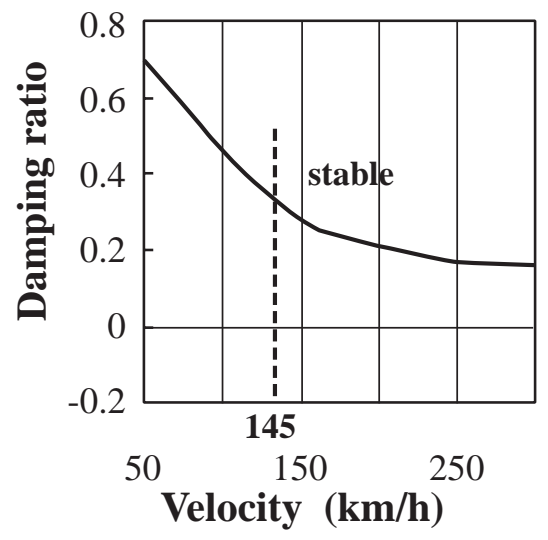

Fig. 11 Influence of velocity

\section{Results of field test}

\subsection{Comparison of forced steering bogie and conventional bogie}

Running tests for the conventional bogie and DC283 forced steering bogie were performed. A running test of

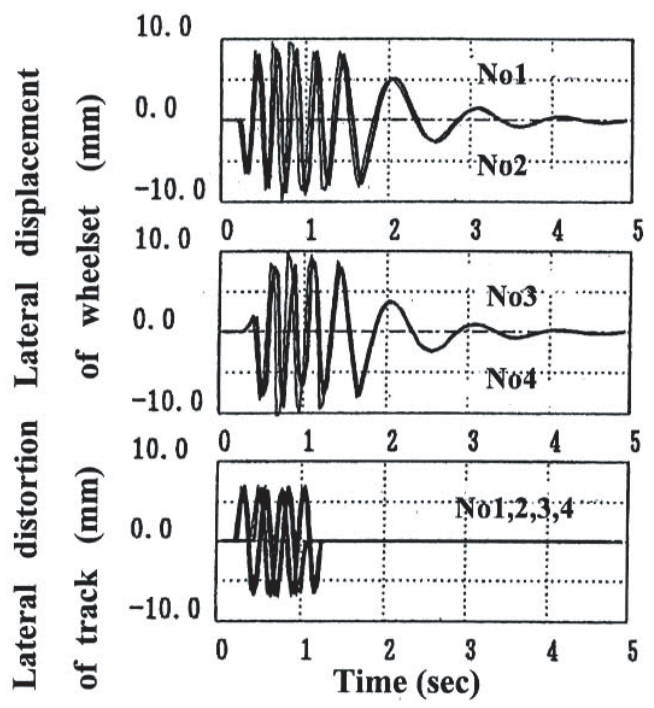

Fig. 12 Waveform of running stability : simulation $(V=270 \mathrm{~km} / \mathrm{h})$ 
$\mathrm{Q}_{1 \mathrm{~L}}$ : Inner lateral force

BTC : Beginning of transition curve

BCC : Beginning of circular curve
$\mathrm{Q}_{1 \mathrm{R}}$ : Outer lateral force

ETC : End of transition curve

ECC : End of circular curve
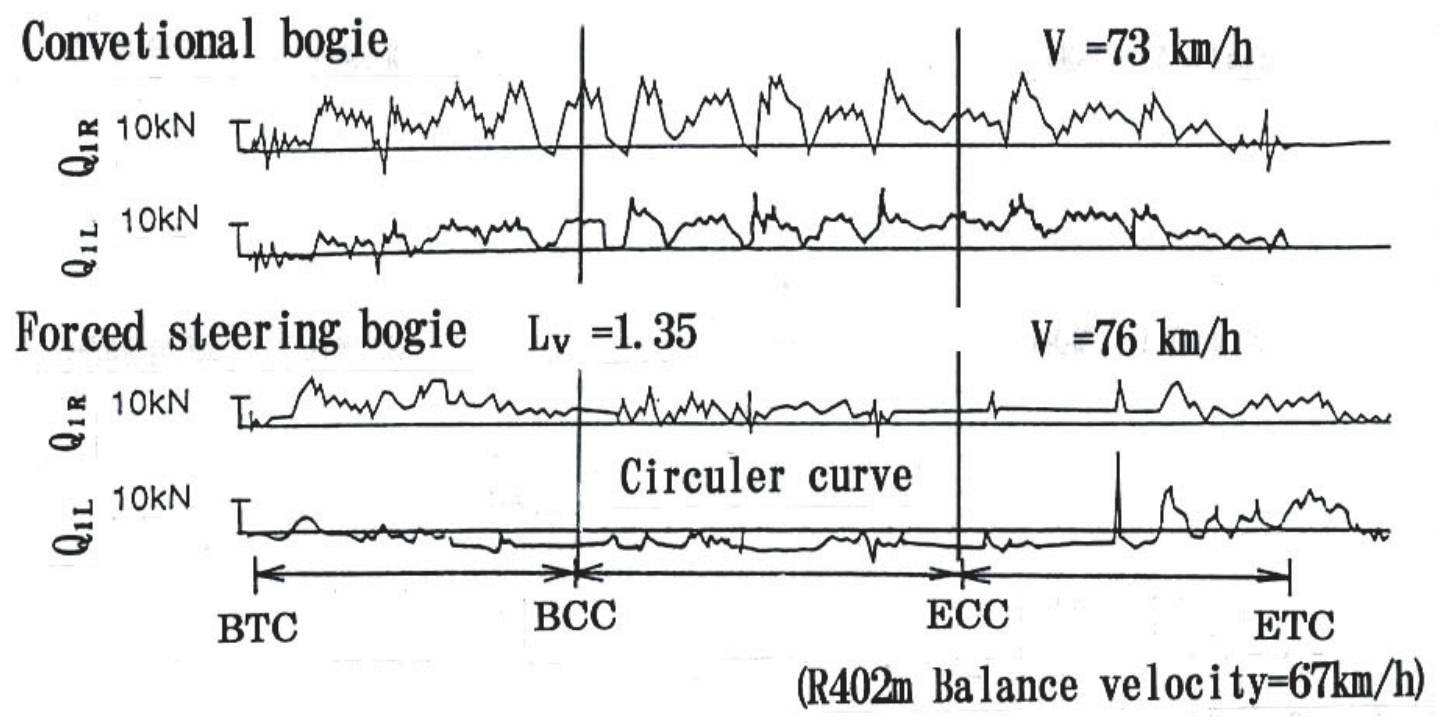

Fig. 13 Wavaform of lateral force : field tests

DC283 forced steering bogie was first performed at the steering ratio of 1.35. Figure 13 shows the waveforms of the lateral force. The lateral force on a circular curve decreases with the DC283 forced steering bogie, in particular. Figure14 shows the mean lateral force in Fig. 13. The mean lateral force for the DC283 forced steering bogie on the outer rail of circular curve decreases to $1 / 2-1 / 3$ that of the conventional bogie. However, the reduction effect of the lateral force on the transition curve is smaller than on the circular curve, to delay the timing of steering when the lateral force becomes 0 , even if the rear bogie exits on the transition curve and the front bogie enters a straight line. When the front bogie leaves the curve and runs on a straight line, a part of carbody is still remaining on the curve. So, the steering device keeps acting the condition on the transition curve. In addition, the inner side wheel has a negative lateral force (refer to the force direction on the wheel in Fig. 5) on the circular curve. This phenomenon is identical with the simulation result $(L v=1.35)$.

\subsection{Relation between lateral force and steering ratio}

Running tests were performed at the steering ratio of 1.35 and 1.2. Figure 16 shows the mean lateral force for different curve radii. The lateral force at the steering ratio of 1.2 on the outer side is larger than that at the steering ratio of 1.35 . Accordingly, the steering ratio of 1.35 was judged as adequate.

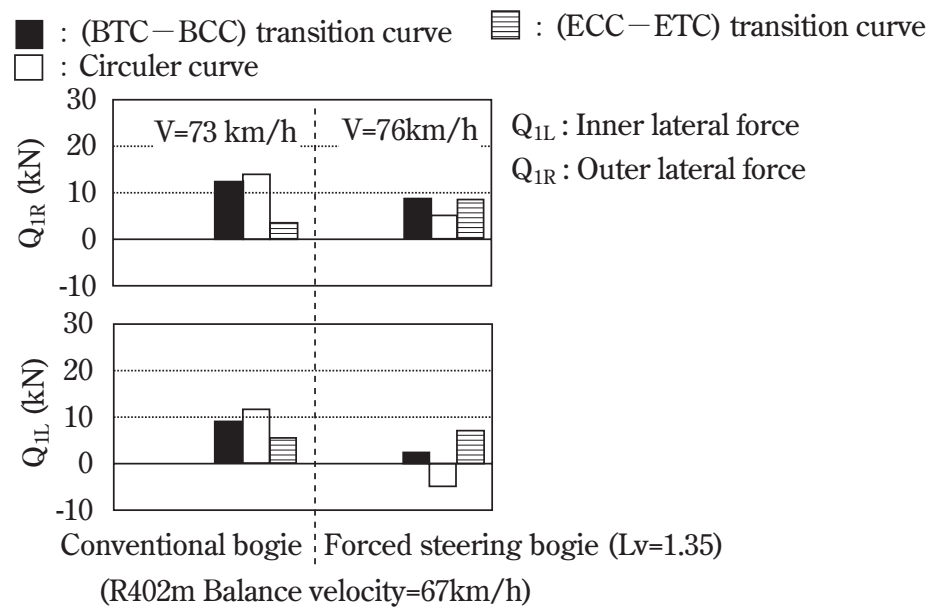

Fig. 14 Comparison of lateral force between conventional bogie and DC283 forced steering bogie : field tests 


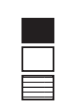

(ECC-ETC) transition curve Circuler curve (BTC-BCC) transition curve

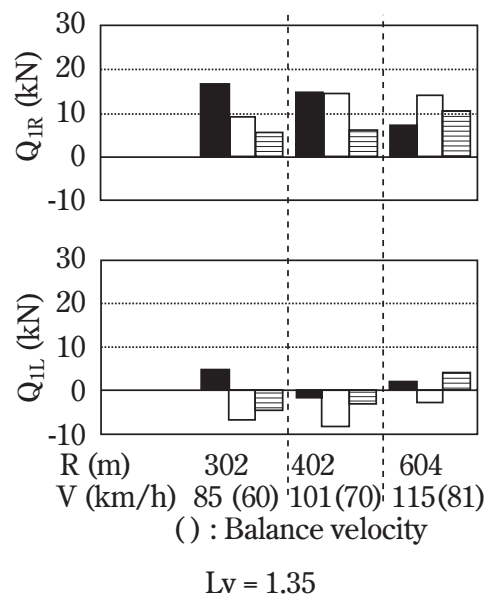

$Q_{1 L}:$ Inner lateral force

$\mathrm{Q}_{1 \mathrm{R}}$ : Outer lateral force

Standard profile $/ 50 \mathrm{~N}$ rail

$\mathrm{R}$ : Radius of curve (m)

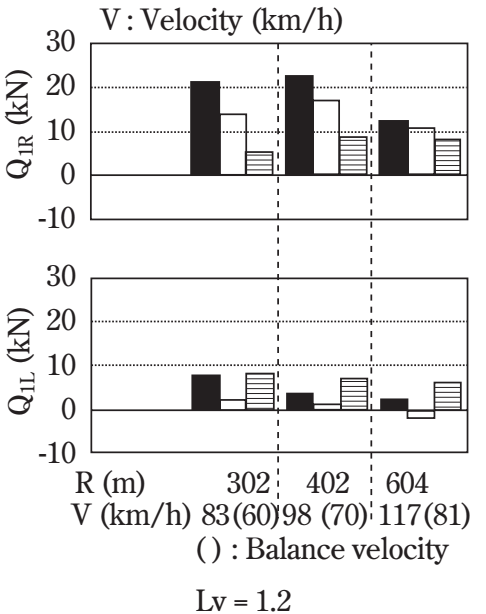

Fig. 15 Mean lateral force for different values of steering ratio : field tests

\subsection{Running stability}

We tested the DC283 forced steering bogies to check the running stability at the maximum speed of $140 \mathrm{~km} / \mathrm{h}$ on a straight line, and confirmed that hunting motion did not occur. Furthermore, in order to examine the influence of the clearance $(1 \mathrm{~mm})$ generated in the joint of steering lever, we tested running stability under the condition that a clearance was artificially set in the joint of steering lever. In this test, the running stability and the curve negotiation performance were also satisfactory.

\section{Conclusions}

We explained an outline of the DC283 forced steering bogie, and the results of analysis and test results in this paper. The conclusions are summarized as follows.

(1) DC283 forced steering bogies can reduce the lateral force on curves.

(2) The mean lateral force decreased to $1 / 2$ - $1 / 3$ compared with that of conventional bogie on circular curves.

(3) The decrease in the lateral force with the forced steering bogie should be verified not only on circular curves but also on transition curves.

(4) To decrease the lateral force more effectively, the steering ratio is set 35 percent $(L v=1.35)$ larger than the value that makes the radial position.

(5) The running stability was satisfactory at the maximum speed of $140 \mathrm{~km} / \mathrm{h}$ in field tests.
As the test results were satisfactory as mentioned above, regular operation of DC283 train started in 1997. JR Hokkaido has introduced 63 cars.

\section{References}

1) Suda, Y., Anderson, J. and Yamada, K.: "Dynamics of Unsymmetrical Suspension Trucks with Semiactive Control," THE DYNAMICS OF VEHICLES on roads and tracks, 13th IAVSD, pp,480-496,1993.

2) Sato, E., Kobayashi, H., Okamoto, I., Tezuka, K., Kakinuma, H.and Tamaoki, T.: "Lateral Force between Wheel and Rail during Curve Negotiation of Limited Express Diesel Car with Forced Steering Bogie," JSME, 64-625, pp, 3563-3570, 1989, (in Japanese).

3) Smith, R.E., "Dynamics Characteristics of Steered Railway Vehicles and Implications to Design," Vehicle System Dynamics, pp.45-70, 1989.

4) Smith,R.E.and Anderson, R.J.: "Characteristics of Guided-Steering Railway Trucks," Vehicle System Dynamics, 17, pp.1-36, 1989.

5) Bell, C.E. and Hedrick, J.K.: "Forced Steering of Rail Vehicles: Stability and Curving Mechanics,"Vehicle System Dynamics, 10, pp.357-386, 1981.

6) Miyamoto, M and Fujimoto, H.: "A Study of Lateral Dynamics Behavior of Rail Vehicle in Curves by Measurement and Computer Simulation," THE DYNAMICS OF VEHICLES on roads and tracks, 11th IAVSD, p.414, 1989. 